\title{
Postvaccination Fever Response Rates in Children Derived Using the Fever Coach Mobile App: A Retrospective Observational Study
}

Sang Hyun $\mathrm{Ahn}^{1 *}$, MD; Jooho Zhiang ${ }^{2 *}$, BS; Hyery $\mathrm{Kim}^{3}$, MD, PhD; Seyun Chang ${ }^{4}$, BS; Jaewon Shin ${ }^{4}$, MD; Myeongchan $\mathrm{Kim}^{4}, \mathrm{MD}$; Yura Lee ${ }^{5}, \mathrm{MD}, \mathrm{PhD}$; Jae-Ho Lee ${ }^{5,6}, \mathrm{MD}, \mathrm{PhD}$; Yu Rang Park ${ }^{7}, \mathrm{PhD}$

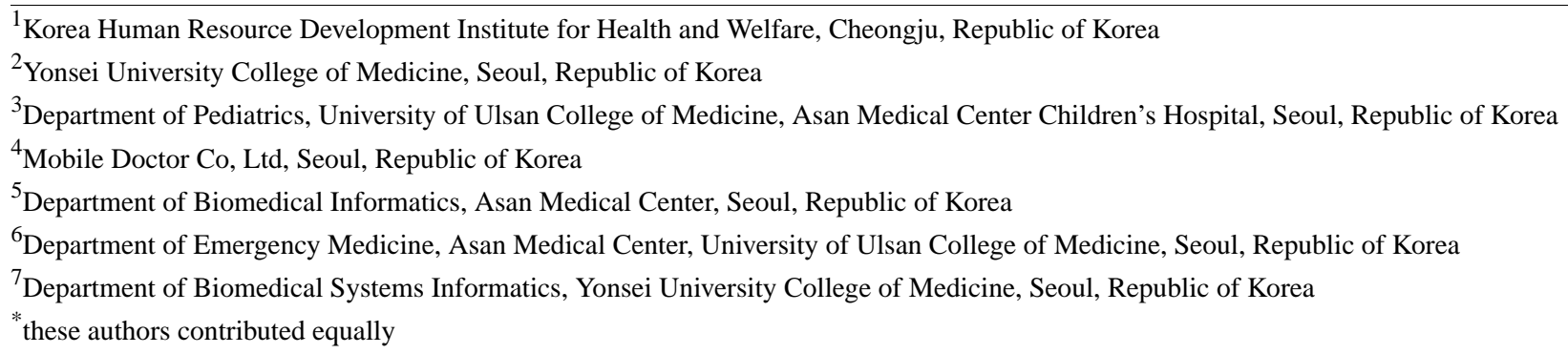

Corresponding Author:

Yu Rang Park, PhD

Department of Biomedical Systems Informatics

Yonsei University College of Medicine

50-1 Yonsei-ro, Seodaemun-gu

Seoul, 03722

Republic of Korea

Phone: 8222282493

Email: yurangpark@yuhs.ac

\section{Related Article:}

This is a corrected version. See correction statement in: https://mhealth.jmir.org/2020/5/e18921/

\section{Abstract}

Background: Postvaccination fever is a mild adverse event that naturally improves without complications, but is highly prevalent and can be accompanied by febrile convulsions in some cases. These adverse effects may cause parents to delay or avoid vaccinating their children.

Objective: This study aimed to identify postvaccination fever patterns and the ability of antipyretics to affect changes in these patterns from data collected from a mobile app named Fever Coach.

Methods: Data provided by parents of feverish children derived from a mobile app, Fever Coach, were used to identify postvaccination fever patterns according to vaccinations and the use of antipyretic drugs. We selected single vaccination records that contained five or more body temperature readings performed within 48 hours of vaccination, and we analyzed postvaccination fever onset, offset, duration, and maximum body temperature. Through observing the postvaccination fever response to vaccination, we identified the effects of antipyretic drugs on postvaccination fever onset, offset, and duration times; the extent of fever; and the rate of decline. We also performed logistic regression analysis to determine demographic variables (age, weight, and sex) involved in relatively high fevers (body temperature $\geq 39^{\circ} \mathrm{C}$ ).

Results: The total number of Fever Coach users was 25,037, with 3834 users having entered single vaccination records, including 4448 vaccinations and 55,783 body temperature records. Most records were obtained from children receiving the following vaccinations: pneumococcus $(n=2069)$; Japanese encephalitis $(n=911)$; influenza $(n=669)$; diphtheria, tetanus, and pertussis $(\mathrm{n}=403)$; and hepatitis A $(\mathrm{n}=252)$. According to the 4448 vaccination records, $3427(77.05 \%)$ children had taken antipyretic drugs, and $3238(89.15 \%)$ children took antibiotics at body temperatures above $38^{\circ} \mathrm{C}$. The number of children taking antipyretics at a body temperature of $38^{\circ} \mathrm{C}$ was more than four times that of those taking antipyretics at $37.9^{\circ} \mathrm{C}(307$ vs 67 cases). The number of instances in which this temperature threshold was reached was more than four times greater than the number when the temperature was $37.9^{\circ} \mathrm{C}$. A comparative analysis of antipyretic and nonantipyretic cases showed there was no difference in onset time; however, offset and duration times were significantly shorter in nonantipyretic cases than in antipyretic cases $(P<.001)$. In nonantipyretic cases, offset times and duration times were 9.9 and 10.1 hours shorter, respectively, than in antipyretic cases. Body temperatures 
also decreased faster in nonantipyretic cases. Influenza vaccine-associated fevers lasted relatively longer, whereas pneumococcus vaccine-associated fevers were relatively short-lived.

Conclusions: These findings suggest that postvaccination fever has its own fever pattern, which is dependent on vaccine type and the presence of antipyretic drugs, and that postvaccination temperature monitoring may ease fever phobia and reduce the unnecessary use of antipyretics in medical care.

(JMIR Mhealth Uhealth 2019;7(4):e12223) doi: $\underline{10.2196 / 12223}$

\section{KEYWORDS}

patient-generated health data; vaccination; postvaccination fever; digital health care; mobile app

\section{Introduction}

The World Health Organization and the Korean Centers for Disease Control and Prevention recommend at least 10 and 14 vaccines, respectively, for routine immunization of children [1]. Despite benefits in preventing serious infectious diseases, vaccinations are also associated with a risk of adverse events in patients. Fever is the most commonly reported adverse event $[2,3]$. The immune system's lymphocyte and polymorphonuclear leukocyte functions improve at body temperatures between $38^{\circ} \mathrm{C}$ and $39^{\circ} \mathrm{C}$. Therefore, the presence of postvaccination fever indicates that the immune system is functioning, but not due to a pathologic reaction [4-6]. There is no agreed definition of a postvaccination fever, but the gold standard definition of a fever is a rectal temperature of $38^{\circ} \mathrm{C}$ or above. Several studies report varying timeframes for postvaccination fever, ranging from within 32 hours, 48 hours, and 4 days of vaccination [7-9].

Postvaccination fever is a mild adverse event that is usually self-limiting over a few days without any specific complications. However, it is highly prevalent and, in some cases, accompanied with febrile convulsions. Furthermore, postvaccination fever may serve as an indicator of infectious disease. For these reasons, postvaccination fever can cause excessive anxiety in parents and caregivers [10-12]. Previous studies have indicated that parent perceptions and fear of fever have not significantly changed over the past 20 years and are still common in the Korean population [13-15]. Postvaccination fever phobia could lead to unnecessary testing, treatment (including the overuse of antipyretics), and emergency department visits, which increase both medical costs and the possibility of side effects $[7,16]$.

Although fever can occur after every vaccination, a higher incidence of fever has been observed in patients receiving pneumococcal and DTaP (diphtheria, tetanus, and pertussis) vaccines than in those receiving other vaccines [17-19], indicating that fever patterns appear to be vaccine-specific. Many febrile diseases have specific fever patterns and progression (continuous, intermittent, remittent) that aid in understanding the pathophysiology of each disease and help to make diagnoses and therapeutic judgments [20,21]. Therefore, knowing the pattern and progress of postvaccination fever is likely to help address issues due to misperceptions regarding vaccination. There have been studies reporting on postvaccination fever frequency, but relatively few studies have reported postvaccination fever patterns [3,20-24]. However, many typical fever patterns can be changed through ingestion of antipyretics such as acetaminophen and steroidal anti-inflammatory drugs. The principal action of these drugs is inhibition of the enzyme cyclooxygenase and reduction of the levels of prostaglandin $\mathrm{E}_{2}$ within the hypothalamus [25]. However, data regarding postvaccination fever patterns and progress are difficult to obtain, with most postvaccination fever-related medical care occurring in outpatient settings where accurate body temperature recordings are not easily obtainable.

Patient-generated health data (PGHD) acquired through high-mobility mediums such as mobile phones, Internet of Things, wearable devices, and mobile apps have recently emerged as alternative methods for collecting data [26-31]. Some studies have shown that these PGHD have improved patient treatment, and studies are underway regarding how PGHD can be linked to routine treatment [32,33]. With immunization, however, obtaining longitudinal and continuous data is difficult. This study aimed to investigate the fever patterns of postvaccination fever through retrospectively analyzing PGHD obtained using Fever Coach, a fever management mobile app, and to analyze changes in fever patterns with the use of antipyretics.

\section{Methods}

\section{Mobile App Description}

Fever Coach is a mobile health care app developed by Mobile Doctor for parents with a feverish child. The app is based on pediatric thermal standards; it assesses a child's condition based on user input and provides guidelines for antipyretic use. The app provides services that support parents' effective and accurate control of common fever symptoms. Fever Coach provides several data services related to managing fever in children, such as microdust concentration status, body temperature information depending on geographical area, disease epidemic alerts, and pediatric health information. The app was made available as a free download from the Google Play Store and Apple App Store. As of June 31, 2017, 197,555 people had registered their child with the app.

We collected vaccination records and records of subsequent postvaccination fever responses and the antipyretics administered. Figure 1 shows the detail screens of the Fever Coach app and the types of data users can enter. All screens of Fever Coach are in Multimedia Appendix 1. The "Today's Records" function provides information for vaccination records. The "Enter the Temperature" function allows the user to provide data concerning the fever response. The "Enter the Dose" function allows the user to provide records of antipyretic use. 
Figure 1. Screenshots of vaccination and fever response in the Fever Coach app. The left screen ("Today's Records"), middle screen ("Enter the temperature"), and right screen ("Enter the dose") have areas for user-input data. The functions corresponding to vaccination data, fever response, and antipyretic data in the three screens are indicated with dotted boxes. The original app showed Korean menu names; for international use, they have been translated into English.

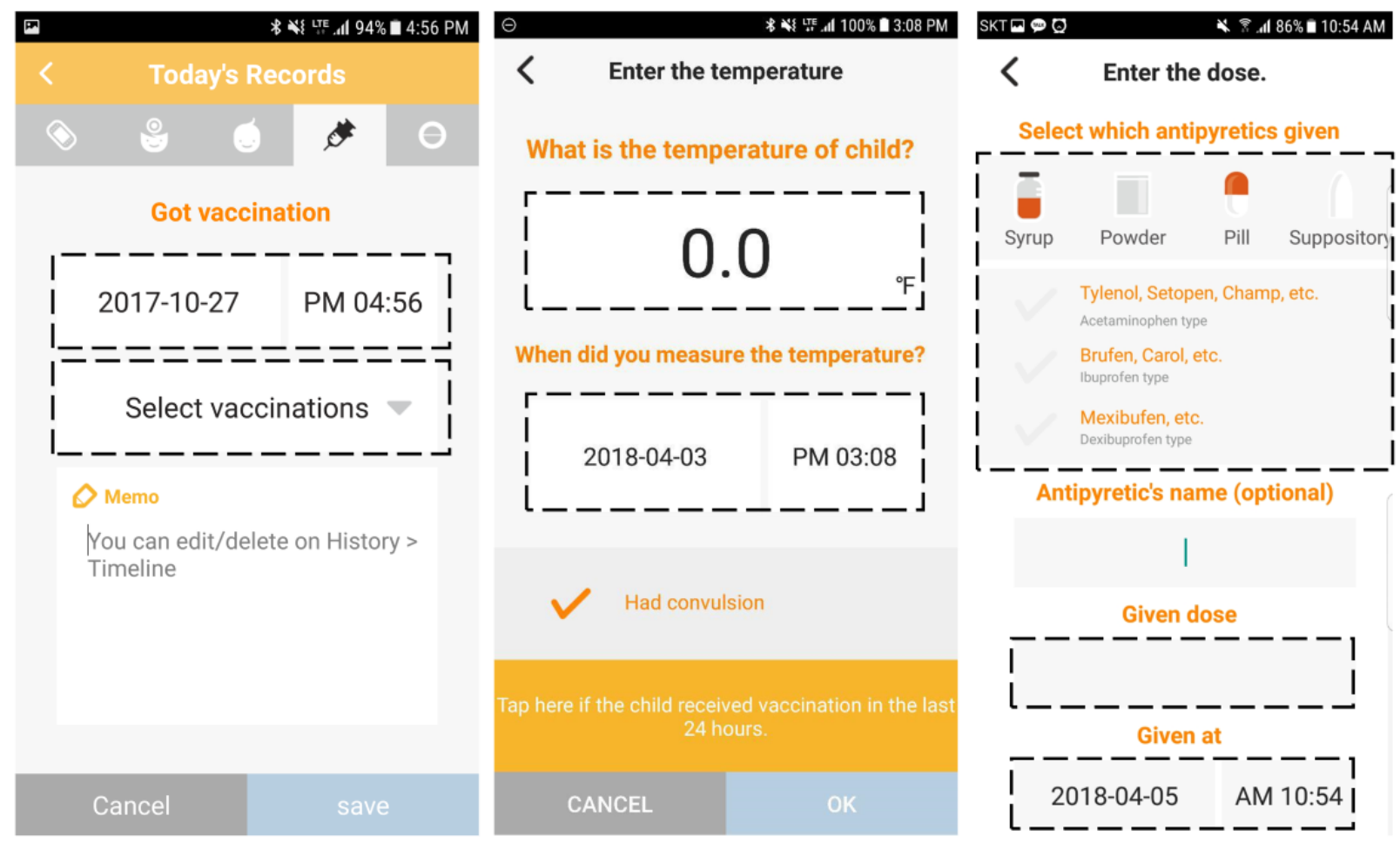

\section{Study Design}

To identify vaccination and antipyretic effects on postvaccination fever response patterns, we analyzed the logs of all users who signed up and registered their child between July 2015 and June 2017. Postvaccination fever usually lasts less than 48 hours [34]; therefore, we examined fever response and antipyretic administration data for 48 hours after the vaccination date entered by the user. For postvaccination fever response analyses, we defined the onset of fever as the point when the body temperature exceeded $38.0^{\circ} \mathrm{C}$, and the offset as the point when the body temperature fell below $38 \cdot 0^{\circ} \mathrm{C}[35,36]$.

Onset time was defined as the time between vaccination and the point at which body temperature exceeded $38.0^{\circ} \mathrm{C}$. If the first record was above $38.0^{\circ} \mathrm{C}$, the time from vaccination to the registration of the data was defined as the onset time. Similarly, offset time was defined as the time between vaccination and the last point at which the body temperature fell below $38.0^{\circ} \mathrm{C}$. The duration time was defined as the time elapsed between onset and offset points (Figure 2). Body temperature values were obtained using linear imputation techniques when they were missing between two actual body temperatures in the neighbors (Figure 2). We used this linear imputation technique on the assumption that the fever progression would show linear characteristics.

This study was approved by the Institutional Review Board of the Asan Medical Center (IRB no. 2018-0179; Seoul, South Korea). The need for informed consent was waived by the Ethics Committee because this study used routinely collected log data that were anonymously managed at all stages, including during data cleaning and statistical analyses. 
Figure 2. Onset, offset, and duration time definitions. The x-axis represents the time since vaccination and the $y$-axis represents the body temperature. The blue dot represents the actual body temperature. The black line between the blue dots is the imputated body temperature.

\section{Temperature}

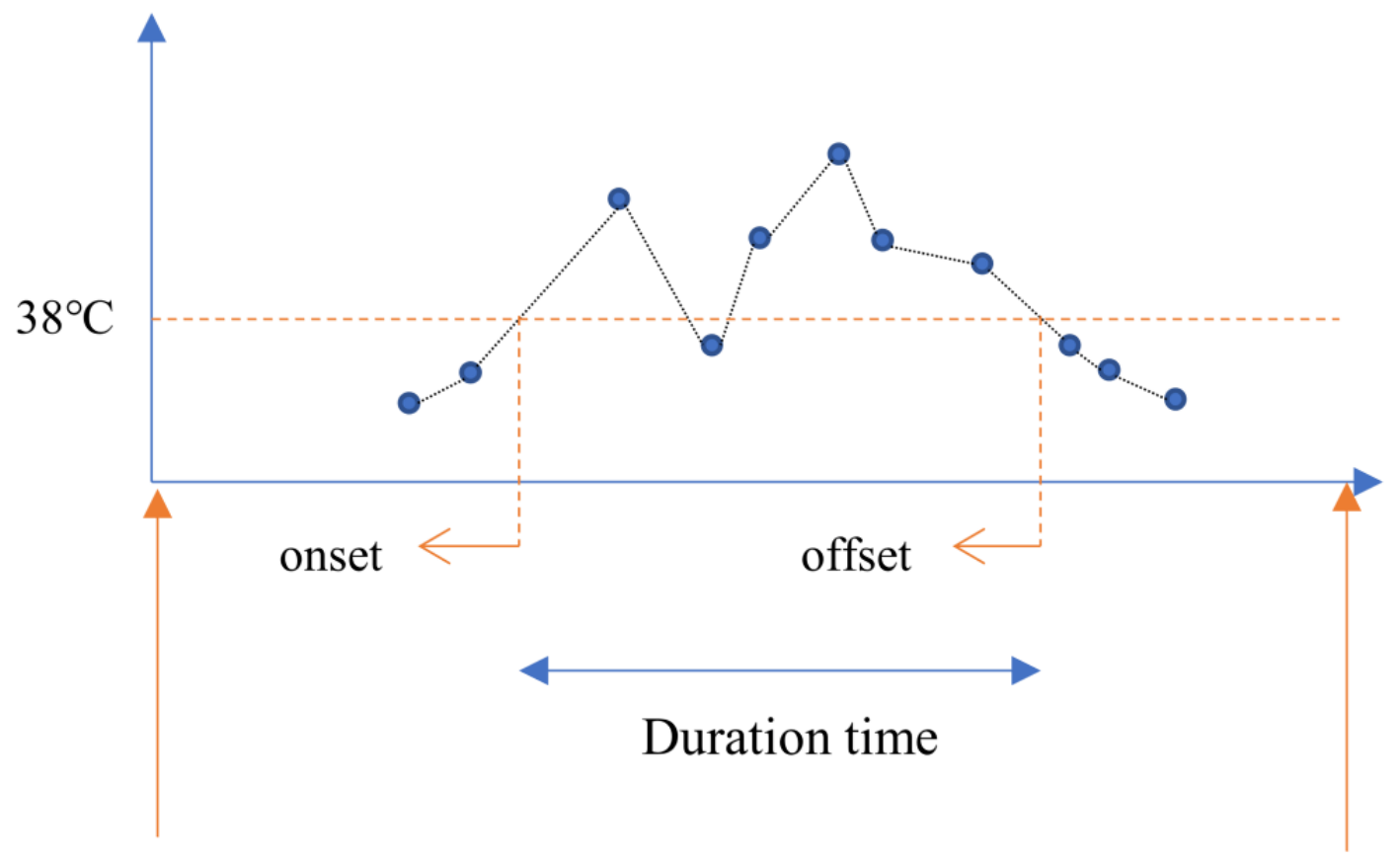

\section{0 hour (vaccination)}

\section{Data Collection and Analysis}

The app allows users to enter data regarding vaccinations, body temperatures, and antipyretic drug administration history. The vaccination record consists of the type and time of vaccine given to a particular child. The body temperature record consists of body temperature and measurement time for a specific child. The antipyretic drug administration record consists of antipyretic agent type, dose, and time. Figure 3 shows the target population selection flow of the study. From July 2015 to June 2017, 65,894 vaccination records were entered, of which 64,003 were vaccination records with basic user information (sex, weight, and age). Among them, the number of single vaccination records was 15,538 . To obtain a sufficient number of body temperature recordings and significant onset and offset values, these data were filtered into 5949 cases with at least five body temperatures recorded within 48 hours after vaccination. Of these, 4448 comprised data-containing points corresponding to onset and offset times. Among these data, bacillus Calmette-Guérin, hepatitis B, measles-mumps-rubella (MMR), Haemophilusinfluenzae type B (Hib), polio, rotavirus, and chickenpox were excluded from the analysis because the number of vaccination records was less than 100 ; therefore, only data regarding DTaP, Japanese encephalitis, pneumococcus, hepatitis $\mathrm{A}$, and influenza were analyzed. Although DTaP and MMR vaccines are combination vaccines, we considered these combination vaccines to be single vaccinations because they are single shots that can be distinguished from multiple vaccinations that involve multiple shots and that vaccines contain a variety of ingredients that can cause side effects [37].
The analysis was undertaken by grouping the data into 3238 cases with antipyretic records and 982 cases with no antipyretic records. For each vaccination record, the sex and age of the child were also collected.

To confirm the postvaccination fever differences between vaccination and antipyretic drug administration, we performed statistical analysis. To compare differences in onset times, offset times, duration times, and maximum temperatures, an independent sample $t$ test was used to determine the degree of difference, while the $P$ value for a two-sided test was used to test for significance. To observe the process of fever for each vaccine record, the onset time was defined as reference time 0 , and body temperature values recorded over the previous 3 hours and the following 24 hours were obtained. Cases were grouped according to whether they were given antipyretic drugs and were reclassified according to vaccine type. Additionally, an ANOVA test was performed to compare maximum temperature and fever duration among the vaccine types. We used a Dunnett T3 post hoc test because the $P$ value of the Levene test was less than .001 , which indicated a violation of the assumption of homogeneity of variance. Lastly, binary logistic regression analysis was performed to determine demographic variables (age, weight, and sex) involved in relatively high fevers (body temperature $\geq 39^{\circ} \mathrm{C}$ ). We performed multiple regression tests to identify multicollinearity between age and weight. If the variance inflation factor (VIF) was less than 10 , it was considered that there was no multicollinearity for those variables. Data were processed and analyzed using $\mathrm{R}$ version 3.5.0, SPSS 21.0, and Python 3.6 (including packages of Pandas 0.22 .0 , NumPy 1.14.3, and Jupyter 1.0.0). 
Figure 3. Data collection flowchart.

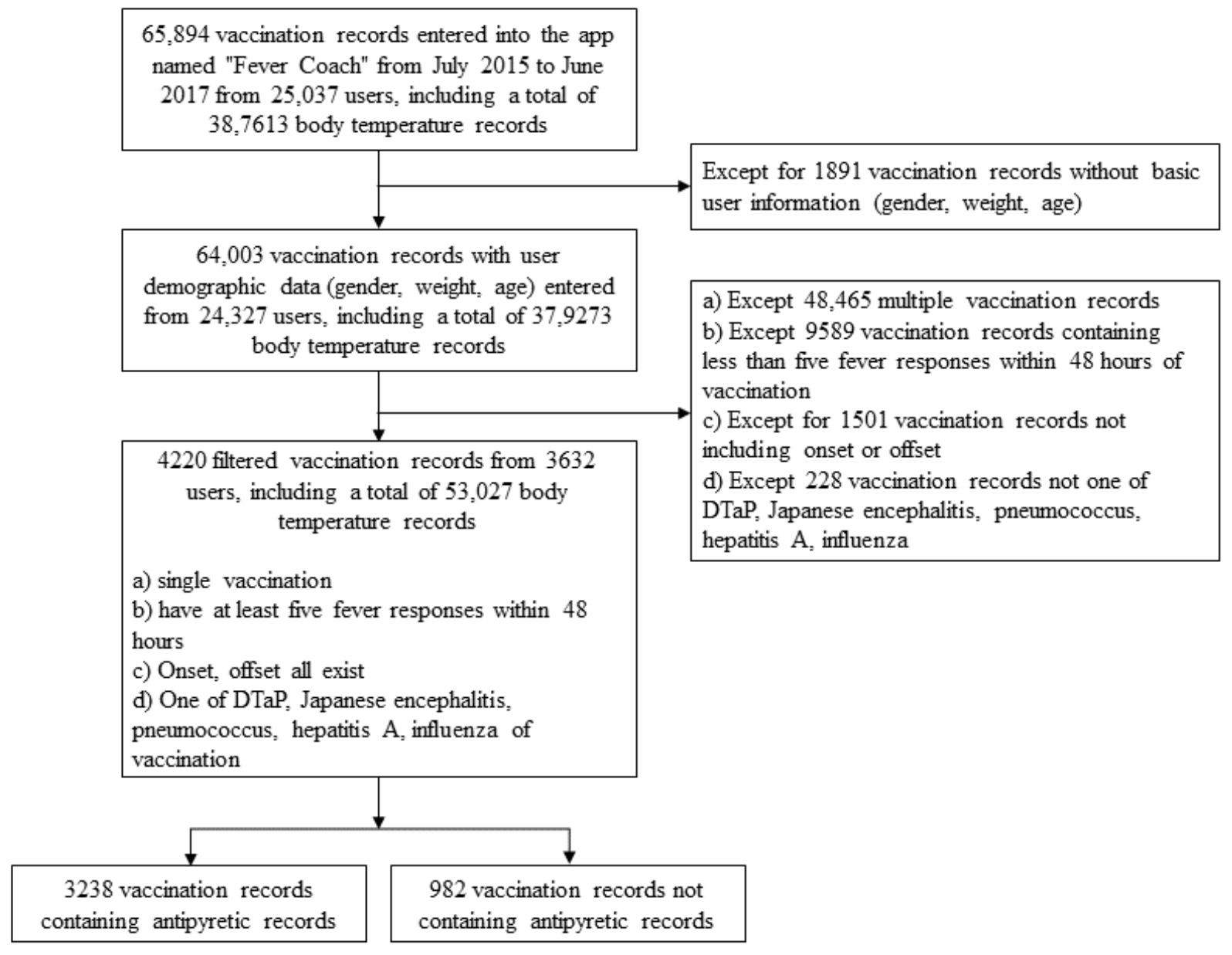

\section{Results}

\section{Overall Characteristics}

During the 24 months of the Fever Coach operation, a total of 25,037 users recorded 65,894 vaccinations involving 387,613 body temperature records for 25,608 children. Of the 64,003 vaccination records for which a child's basic information was available, 15,538 (24.27\%) were single vaccination records. Of the total number of enrolled children, there were 3834 (14.97\%) children with five or more body temperature records at onset and offset, with 4448 vaccination records and 55,783 body temperature records (Table 1). The age at vaccination was significantly different in relation to the vaccine types. The proportion of males in this study was $60.12 \%$ (2193/3648). The proportion of vaccination records with antipyretic drugs was $77.05 \%$ (3427/4448). The majority of records were from children receiving the following vaccinations: pneumococcus $(n=2069)$, Japanese encephalitis $(n=911)$, influenza $(n=669)$, $\operatorname{DTaP}(n=403)$, and hepatitis A $(n=252)$. Each of the remaining single vaccinations had less than 100 records each. 
Table 1. Basic characteristics according to vaccine type and the presence of antipyretic drugs.

\begin{tabular}{|c|c|c|c|c|c|c|c|c|c|}
\hline \multirow{2}{*}{$\begin{array}{l}\text { Type of vaccination } \\
\text { (number of records, } \\
\text { number of children) }\end{array}$} & \multicolumn{2}{|c|}{ Age (months) } & \multirow{2}{*}{$\begin{array}{l}\text { Sex (male), } \\
\mathrm{n}(\%)\end{array}$} & \multicolumn{2}{|l|}{ Weight $(\mathrm{kg})$} & \multirow{2}{*}{$\begin{array}{l}\text { Vaccination } \\
\text { records with } \\
\text { antipyretics, } \\
\mathrm{n}(\%)\end{array}$} & \multirow{2}{*}{$\begin{array}{l}\text { Body tempera- } \\
\text { ture records, } \\
\text { mean (SD) }\end{array}$} & \multicolumn{2}{|c|}{ Body temperature $\left({ }^{\circ} \mathrm{C}\right)$} \\
\hline & $\begin{array}{l}\text { Median } \\
\left(\mathrm{IQR}^{\mathrm{a}}\right)\end{array}$ & $\begin{array}{l}\text { Mean } \\
\left(\mathrm{SD}^{\mathrm{b}}\right)\end{array}$ & & $\begin{array}{l}\text { Median } \\
\text { (IQR) }\end{array}$ & Mean (SD) & & & $\begin{array}{l}\text { Median } \\
\text { (IQR) }\end{array}$ & $\begin{array}{l}\text { Mean } \\
(\mathrm{SD})\end{array}$ \\
\hline $\mathrm{BCG}^{\mathrm{c}}(16,13)$ & & & 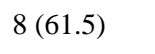 & 7.7 & 8. & 5) & 10. & $37.7(0.9)$ & $37.6(0.8)$ \\
\hline Chickenpox $(31,28)$ & $14.3(6.2)$ & $18.6(12.3)$ & $19(67.9)$ & $10.1(35.0)$ & $11.3(4.7)$ & $29(93.5)$ & $14.0(7.7)$ & $38.1(1.0)$ & $38.1(0.8)$ \\
\hline $\operatorname{DTaP}^{\mathrm{d}}(394,352)$ & $13.3(14.8)$ & $14.9(13.0)$ & $212(60.2)$ & $9.5(27.8)$ & $9.5(3.1)$ & $318(80.7)$ & $12.7(7.2)$ & $37.9(0.8)$ & $37.9(0.7)$ \\
\hline Hepatitis B $(61,55)$ & $10.7(7.3)$ & $14.5(14.4)$ & $37(67.3)$ & $9(22.3)$ & $9.7(3.7)$ & $54(88.5)$ & $12.1(9.2)$ & $37.9(0.9)$ & $37.9(0.7)$ \\
\hline Hepatitis A $(247,223)$ & $19.8(9.1)$ & $20.4(6.2)$ & $130(58.3)$ & $11(16.0)$ & $11(1.6)$ & $229(92.7)$ & $14.3(9.8)$ & $38(1.0)$ & $38(0.7)$ \\
\hline $\operatorname{Hib}^{\mathrm{e}}(47,40)$ & 15.3 & 14. & 20 & 9.7 & $9.4(2.0)$ & 43 & 12.1 & $37.9(0.9)$ & $37.9(0.7)$ \\
\hline Influenza $(655,587)$ & $17.2(7.9)$ & $28(20.8)$ & $325(55.4)$ & $11.5(39.0)$ & $12.5(4.3)$ & $576(87.9)$ & $13.3(8.1)$ & $38(0.9)$ & $38(0.8)$ \\
\hline $\begin{array}{l}\text { Japanese encephalitis } \\
(890,793)\end{array}$ & $17.2(7.9)$ & $19.1(8.1)$ & $422(53.2)$ & $10.4(23.5)$ & $10.7(1.8)$ & $792(89.0)$ & $12.0(7.5)$ & $37.9(0.8)$ & $37.9(0.7)$ \\
\hline $\operatorname{MMR}^{\mathrm{f}}(31,28)$ & $16.1(10.0)$ & $23.4(15.8)$ & $15(53.6)$ & $11(19.0)$ & $11.9(2.8)$ & $29(93.5)$ & $13.3(6.2)$ & $38.1(1.1)$ & $38.1(0.8)$ \\
\hline $\begin{array}{l}\text { Pneumococcus (2034, } \\
1771)\end{array}$ & $7.1(11.0)$ & $9.3(8.1)$ & $981(55.5)$ & $8(32.0)$ & $8.2(2.5)$ & $1323(65.0)$ & $12.3(7.7)$ & $37.7(0.7)$ & $37.8(0.6)$ \\
\hline Polio $(19,17)$ & $12.3(11.2)$ & $12.1(9.2)$ & $11(64.7)$ & $8.8(14.0)$ & $9.3(2.7)$ & $11(57.9)$ & $11.5(6.5)$ & $37.7(0.7)$ & $37.7(0.7)$ \\
\hline Rotavirus $(23,22)$ & $5.2(4.4)$ & $5.5(3.1)$ & $13(59.1)$ & $7(11.5)$ & $7.1(1.7)$ & $13(56.5)$ & $9.6(5.1)$ & $37.7(0.9)$ & $37.7(0.5)$ \\
\hline Total $(4448,3648)$ & $13.5(13.0)$ & $15.4(13.3)$ & $2193(60.1)$ & $9.7(3.5)$ & $9.7(3.2)$ & $3427(77.0)$ & $12.5(7.8)$ & $37.7(0.7)$ & $37.9(0.7)$ \\
\hline
\end{tabular}

${ }^{\mathrm{a}} \mathrm{IQR}$ : interquartile range.

${ }^{\mathrm{b}} \mathrm{SD}$ : standard deviation.

${ }^{\mathrm{c}}$ BCG: bacille Calmette-Guérin.

${ }^{\mathrm{d}}$ DTaP: diphtheria, tetanus, pertussis.

${ }^{\mathrm{e}} \mathrm{Hib}$ : Haemophilusinfluenzae type b.

${ }^{\mathrm{f}} \mathrm{MMR}$ : measles, mumps, and rubella.

\section{Antipyretic Drug Administration Pattern}

After vaccination, $14.66 \%$ (475/3238) of children were administered the first antipyretic drug within 1 hour, and more than $50 \%$ of children were administered antipyretic drugs within 10 hours. By 10 hours, the number of children treated with antipyretic drugs increased gradually, but decreased from 11 hours to less than $10 \%$ at 41 hours. A total of $2887(89.16 \%)$ children used antipyretics when the postvaccination body temperature was $38.0^{\circ} \mathrm{C}$ or above (Figure 4). The number of children taking antipyretics at a body temperature of $38^{\circ} \mathrm{C}$ was more than four times that of those taking antipyretics at $37.9^{\circ} \mathrm{C}$ (307 vs 67 cases). The percentages of children who received antipyretic drugs were $0.71 \%(23 / 3238)$ and $0.49 \%(16 / 3238)$ at body temperatures lower than $37^{\circ} \mathrm{C}$ and above $40^{\circ} \mathrm{C}$, respectively.

\section{Comparison of Onset, Offset, and Duration Times Among Vaccination Records With and Without Antipyretic Administration}

There were significant differences in offset times, duration times, and maximum temperatures between groups that had taken antipyretics and those that had not, but there was no significant difference in onset times (Figure 5). Differences between groups were marked, especially maximum temperatures that affected offset time and duration. Children vaccinated against hepatitis $\mathrm{A}$ showed the greatest difference in maximum temperature (mean $39.0^{\circ} \mathrm{C}$, SD $0.6^{\circ} \mathrm{C}$ vs mean $38.4^{\circ} \mathrm{C}, \mathrm{SD} 0.4^{\circ} \mathrm{C}$ in children who had been administered antipyretic drugs compared to children who had not been administered antipyretic drugs). The postvaccination fever duration was three times longer in children who were administered antipyretic drugs than in children who were not administered antipyretic drugs (mean 17.4, SD 11.8 hours vs mean 4.9, SD 7.5 hours, with antipyretic drugs compared to without antipyretic drugs).

Postvaccination fever differences between onset, offset, and duration times associated with each vaccine showed statistically significant differences in offset times and duration between groups $(P<.001)$ (Multimedia Appendix 2). Offset and duration times for children who were not administered antipyretics were significantly shorter than for those who were administered antipyretics. There was no significant difference in onset time between the groups. 
Figure 4. Time of first administration of antipyretic after vaccination and body temperature at the time of antipyretic use.
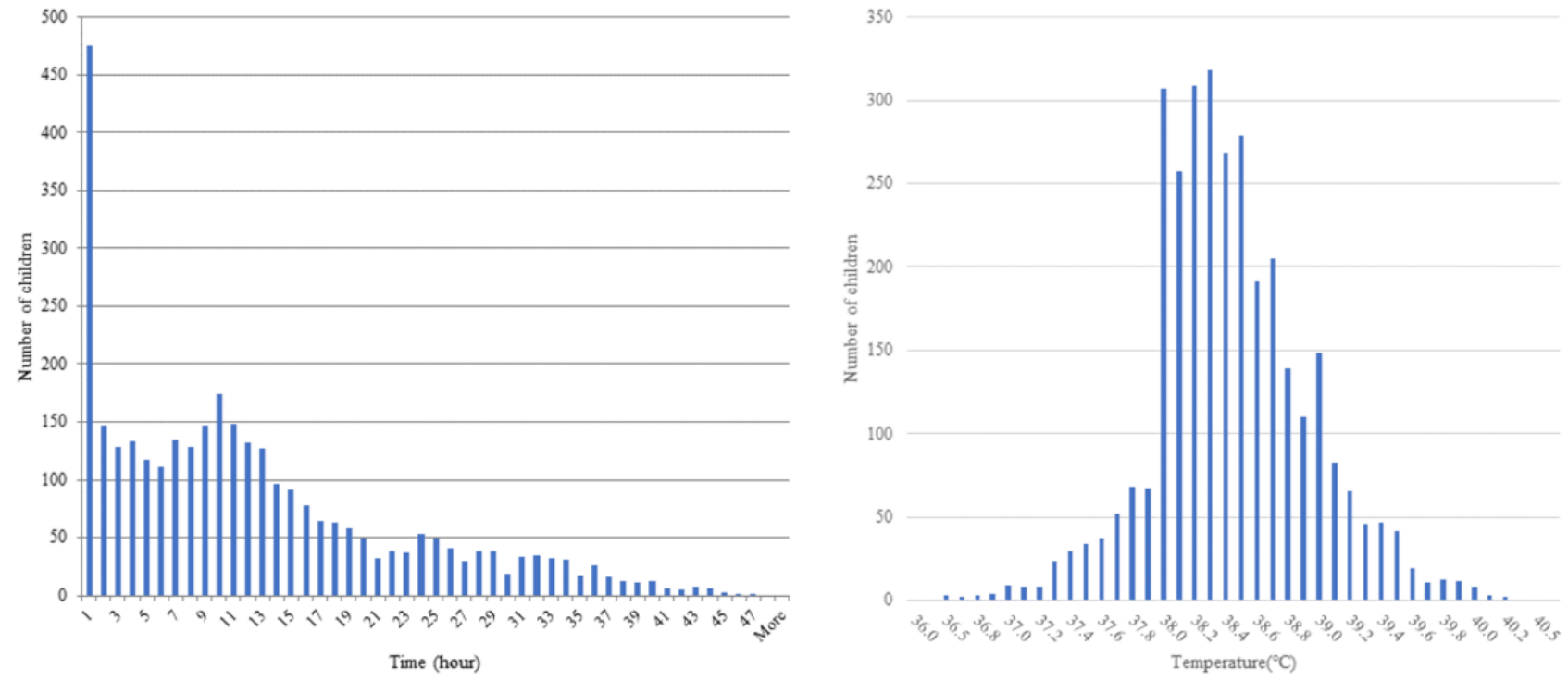

Figure 5. Comparison of onset, offset, duration times, and maximum temperatures among vaccine types, and the effects of antipyretics on postvaccination fever response. From left to right: box plots of onset, offset, duration times, and maximum body temperature are depicted. The bar indicates the median; $\mathrm{x}$ indicates the mean.
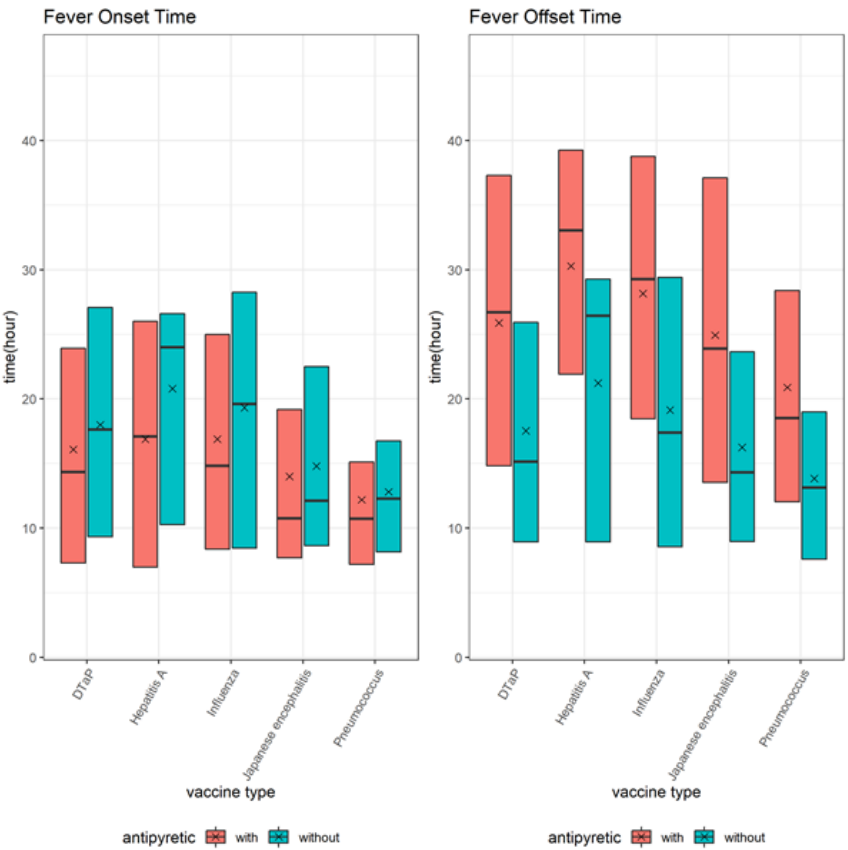
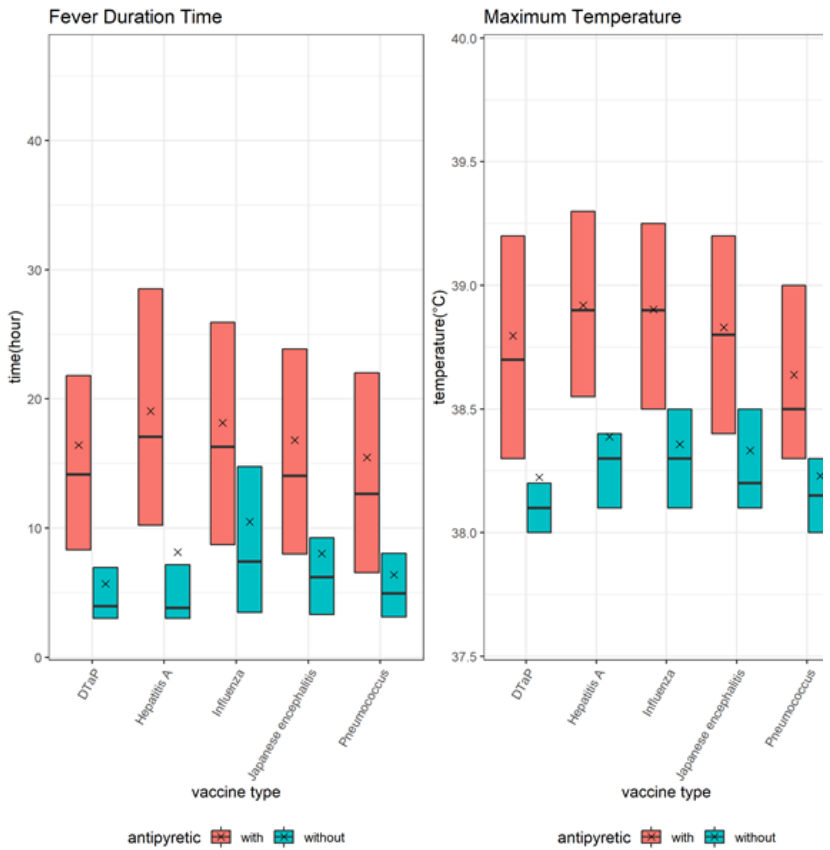

We found statistically significant differences in maximum temperature and fever duration among vaccines (both $P<.001$ ). In the postanalysis grouping, maximum temperature and fever duration decreased in the following order: hepatitis A, influenza, Japanese encephalitis, DTaP, and pneumococcus (Table 2).

We used logistic regression to determine the demographic variables involved in relatively high fevers (Table 3). There was no multicollinearity between age and weight (age $\mathrm{VIF}=4.38$, weight $\mathrm{VIF}=4.38$ ). Sex was not a significant variable in all groups, and age was not significant except in children who were administered the pneumococcus vaccine. Weight was statistically significant in all cases except in those receiving the hepatitis A vaccine. 
Table 2. Comparison of maximum temperature and fever duration among vaccine types.

\begin{tabular}{lccc}
\hline Vaccine type & Mean (SD) & $F_{4,4215}$ & \multicolumn{2}{c}{ value $^{\mathrm{a}}$} \\
\hline Maximum temperature $\left({ }^{\circ} \mathbf{C}\right)$ & $38.5(0.5)$ & 94.7 & \\
Pneumococcus & $38.7(0.6)$ & \\
DTaP & $39.0(0.6)$ & \\
Hepatitis A & $38.9(0.6)$ & \\
Influenza & $38.8(0.5)$ & 62.8 \\
Japanese encephalitis & & \\
Fever duration (hours) & $8.5(10.5)$ & \\
Pneumococcus & $11.3(11.1)$ & \\
DTaP & $16.4(12.0)$ & \\
Hepatitis A & $14.6(12.3)$ & \\
Influenza & $12.8(11.7)$ & \\
Japanese encephalitis & & \\
\hline
\end{tabular}

${ }^{a}$ As a result of the post hoc test (Dunnett T3), maximum temperature and fever duration showed the following: Hepatitis A, influenza > Japanese encephalitis, DTaP > pneumococcus. 
Table 3. Variables involved in relatively high postvaccination fever $\left(\geq 39^{\circ} \mathrm{C}\right){ }^{\mathrm{a}}$

\begin{tabular}{|c|c|c|c|}
\hline Vaccine type and variable & B (SE) & $P$ value & Adjusted odds ratio $(95 \% \mathrm{CI})$ \\
\hline \multicolumn{4}{|l|}{ Pneumococcus } \\
\hline Age & $0.056(0.014)$ & $<.001$ & $1.057(1.029-1.086)$ \\
\hline Weight & $0.210(0.042)$ & $<.001$ & $1.233(1.135-1.340)$ \\
\hline Sex & $-0.096(0.121)$ & .42 & $0.908(0.716-1.152)$ \\
\hline \multicolumn{4}{|l|}{ DTaP } \\
\hline Age & $-0.004(0.018)$ & .82 & $0.996(0.960-1.033)$ \\
\hline Weight & $0.234(0.083)$ & .005 & $1.263(1.075-1.485)$ \\
\hline Sex & $-0.331(0.231)$ & .15 & $0.718(0.457-1.129)$ \\
\hline \multicolumn{4}{|l|}{ Japanese encephalitis } \\
\hline Age & $0.006(0.012)$ & .59 & $1.006(0.984-1.029)$ \\
\hline Weight & $0.108(0.052)$ & .03 & $1.114(1.005-1.234)$ \\
\hline Sex & $-0.070(0.142)$ & .62 & $0.933(0.706-1.233)$ \\
\hline \multicolumn{4}{|l|}{ Hepatitis A } \\
\hline Age & $0.036(0.024)$ & .13 & $1.037(0.989-1.088)$ \\
\hline Weight & $0.011(0.094)$ & .90 & $1.011(0.841-1.217)$ \\
\hline Sex & $0.158(0.264)$ & .55 & $1.171(0.698-1.966)$ \\
\hline \multicolumn{4}{|l|}{ Influenza } \\
\hline Age & $-0.016(0.010)$ & .09 & $0.984(0.966-1.003)$ \\
\hline Weight & $0.104(0.047)$ & .02 & $1.109(1.102-1.216)$ \\
\hline Sex & $0.002(0.160)$ & .98 & $1.002(0.732-1.372)$ \\
\hline \multicolumn{4}{|l|}{ All } \\
\hline Age & $-0.004(0.006)$ & .43 & $0.996(0.985-1.007)$ \\
\hline Weight & $0.226(0.025)$ & $<.001$ & $1.254(1.195-1.316)$ \\
\hline Sex & $-0.106(0.071)$ & .13 & $0.899(0.782-1.034)$ \\
\hline
\end{tabular}

${ }^{\mathrm{a} C I}$ : confidence interval; DTaP: diphtheria, tetanus, pertussis; SE: standard error. 
Figure 6. Body temperature graph over time for each vaccine showing the effects of antipyretic administration. The empty circle indicates the mean; the error bar represents a $95 \%$ confidence interval.
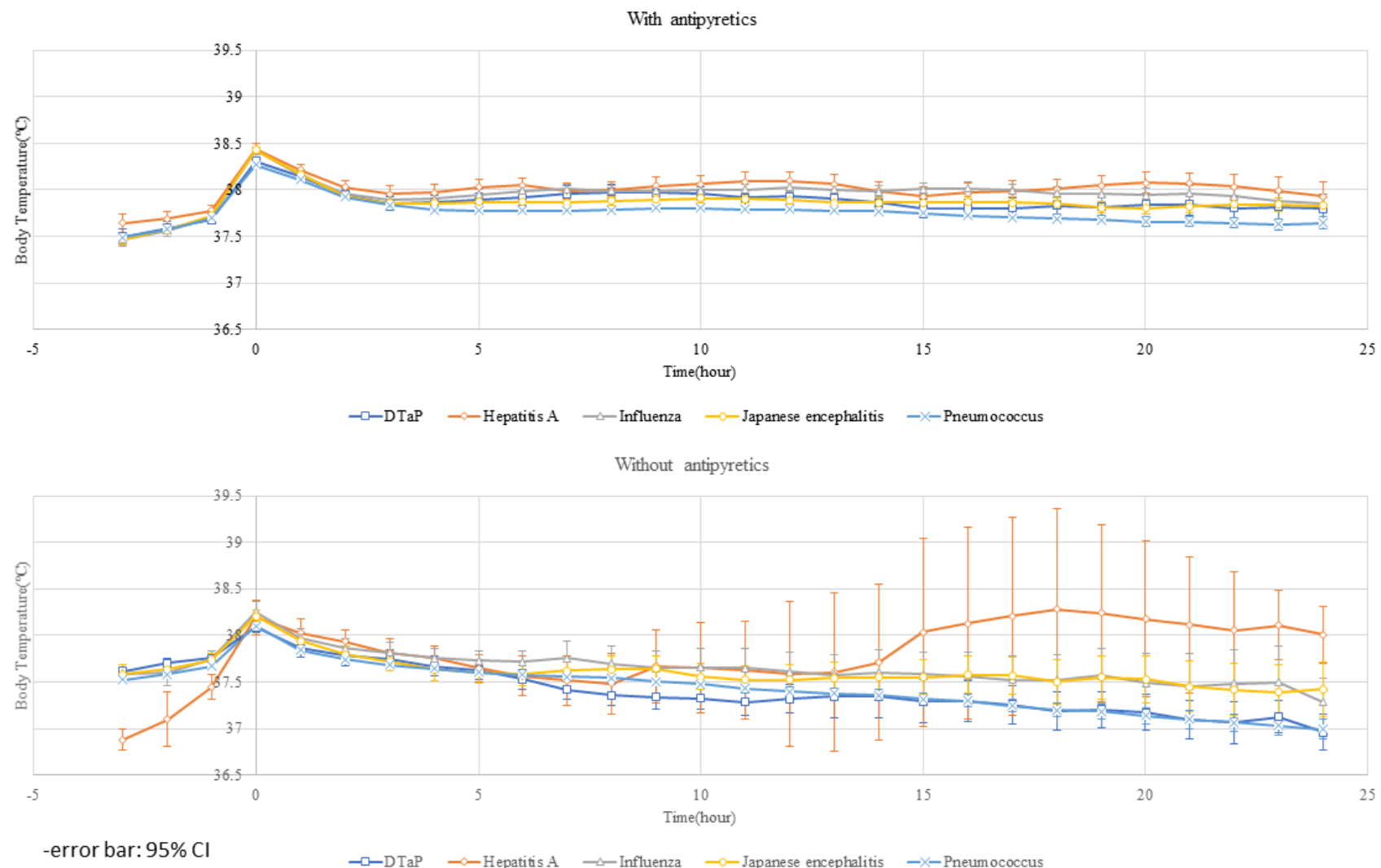

\section{Comparison of Fever Response}

Figure 6 shows the result of plotting body temperature over time for each vaccine type and the effects of antipyretic drug administration. In cases where antipyretics were not administered, especially concerning DTaP and pneumococcus, the slope of the graph was steeper than in cases that included antipyretics, indicating that body temperature dropped more rapidly in children who were not administered antipyretic drugs (DTaP $R^{2}: .84$ vs .00; pneumococcus $R^{2}: .83$ vs .14). In the antipyretic use group, the mean body temperature was $37.5^{\circ} \mathrm{C}$ or above even after 24 hours, but in the nonantipyretic use group, the mean body temperature dropped below $37.5^{\circ} \mathrm{C}$ before 20 hours for all vaccines except hepatitis A. In comparing vaccines, we found that postvaccination fever associated with the influenza vaccine tended to be relatively long-lasting, and that the pneumococcus vaccine showed a relatively rapid decline.

\section{Comparison of the Effects of Antipyretics on Postvaccination Fever Response}

Multimedia Appendix 2 shows the comparison of onset, offset, duration times, maximum temperatures among vaccine types, and the effects of antipyretics on postvaccination fever response. Postvaccination fever in children who were administered antipyretics exhibited a mean onset time of between 9.0 and 13.7 hours, a mean offset time of between 20.4 and 31.1 hours, a mean duration time of between 11.5 and 17.4 hours, and a maximum temperature of between $38.7^{\circ} \mathrm{C}$ and $39^{\circ} \mathrm{C}$. The mean postvaccination fever onset time was not significantly different between children who were administered antipyretics and those who were not (mean 10.9, SD hours 9.9 vs mean 10.4, SD hours, $9.3 P=.12$ ), but the mean offset time and duration were significantly different (offset time: mean 24.3, SD hours 13.4 vs mean 13.6, SD 9.9 hours, $P<.001$; duration: mean 13.4, SD 11.9 hours vs mean 3.2 , SD 5.0 hours, $P<.001$ ). The maximum body temperatures at onset time were mean $38.8^{\circ} \mathrm{C}\left(\mathrm{SD} 0.6^{\circ} \mathrm{C}\right)$ in the antipyretic group and mean $38.3^{\circ} \mathrm{C}\left(\mathrm{SD} 0.5^{\circ} \mathrm{C}\right)$ in the nonantipyretic group, with a statistically significant difference between the two groups $(P<.001)$.

\section{Discussion}

\section{Principal Findings}

We identified different postvaccination fever responses for each vaccine using data collected through the mobile app Fever Coach. For example, in relation to the hepatitis A vaccine, the postvaccination fever maximum temperature was statistically significantly higher and was of a longer duration than that for other vaccines $(P<.001)$. We were also able to clearly identify differences among postvaccination fevers with and without antipyretic administration; offset, duration times, and maximum temperature were significantly different between groups $(P<.001)$. Additionally, we presented new evidence from large-scale PGHD concerning fever duration and maximum temperatures reached after a single vaccination. The postvaccination fever duration was generally 48 hours but, for all single vaccinations, the longest postvaccination fever duration was mean 16.4 (SD 12.0) hours, and the highest maximum temperature was mean $39.0^{\circ} \mathrm{C}\left(\mathrm{SD} 0.6^{\circ} \mathrm{C}\right)$. In terms of informatics, an additional contribution of this study is that 
the majority of users verified the pediatric fever level based on the PGHD. This study is original compared with previous studies for the following reasons: we used actual postvaccination fever response data without any clinical intervention; we analyzed large-scale postvaccination fever responses based on real-world data rather than relying on data from a small, clinical-based group; and our study used data derived from anyone using a mobile phone and not just from a specific hospital or specific patient area, which allowed us to analyze individual data covering a larger area than from data from a single institution or specific area.

\section{Characteristics of Postvaccination Fever and Its Natural Course According to Vaccine Type}

Because most previous studies have been conducted to determine vaccine safety, they primarily discussed the frequency and severity of postvaccination fever and did not provide medical direction to parents or caregivers. This study showed that postvaccination fever associated with each vaccine has a unique fever pattern in terms of maximum temperature and duration.

Among all vaccines included in the study, the postvaccination fever in the nonantipyretic use group showed a mean onset time of 9.4 hours (pneumococcal vaccine) to 15.3 hours (hepatitis A vaccine), a mean offset time of 12.5 hours (pneumococcal vaccine) to 20.1 hours (hepatitis A vaccine), and a mean duration time of 2.5 hours (DTaP vaccine) to 6.1 hours (influenza vaccine) (details in Multimedia Appendix 2). These values are considered consistent with associated fever and vaccination administration if the fever occurs within 24 hours of vaccination and if the temperature falls within 24 hours after onset in general practice [38]. The characteristics of postvaccination fever according to vaccine type in all data were as follows: the maximum temperature was highest for children vaccinated against hepatitis $\mathrm{A}$ and lowest for children receiving the pneumococcal vaccine. Children receiving the pneumococcal vaccine are known to have a high incidence of postvaccination fever; therefore, it is not uncommon for clinical practitioners to give a warning before and after vaccination and recommend that parents administer antipyretic agents when fever occurs $[19,39]$. However, the results of this study showed that the mean temperature following pneumococcal vaccination was significantly lower than for other vaccinations, regardless of the use of antipyretics. Fever duration was longest for hepatitis A and influenza, followed by Japanese encephalitis, pneumococcus, and DTaP vaccine. Postvaccination fever associated with pneumococcal vaccine had a lower maximum temperature and a shorter duration than postvaccination fever associated with hepatitis A vaccine but fell below the fever onset temperature $\left(38^{\circ} \mathrm{C}\right)$ within 24 hours after fever occurred. If parents were more aware of this natural course of postvaccination fever, they may be less anxious and reduce the use of antipyretics, thereby reducing unnecessary medical care $[40,41]$. We would expect parents to have a more positive outlook regarding vaccinations once their fears concerning fever had been more fully addressed [15].

Our results showed that, as a child's weight increased, there was a high probability that a relatively high fever with a body temperature of less than $39^{\circ} \mathrm{C}$ would occur, regardless of age or sex (Table 3). It is known that the incidence of fever (especially a high fever with a body temperature of $39^{\circ} \mathrm{C}$ ) tends to increase in children receiving the pneumococcal booster vaccination after 1 year of age, which is thought to be due to the booster effect, as the immune function matures and the number of vaccinations increase with age [24]. Here, however, only weight was significantly associated with the risk of high fever. Generally, a child's age and weight are linearly correlated. The immune response to vaccination is known to be higher for girls than for boys $[42,43]$, but there was no difference in the frequency of relatively high fevers between the sexes.

\section{Postvaccination Fever and Antipyretics}

The duration of postvaccination fever in children who were administered antipyretics tended to be more prolonged than for those who were not administered antipyretics in this study. However, the actual body temperature at onset time and the maximum temperature were significantly higher in children who were administered antipyretics than in those who were not administered antipyretics (mean 38.8, SD 0.6 vs mean 38.3, SD 0.5 , respectively, $P<.001$ ). Therefore, it is possible that if the period of decrease to the fever onset temperature $\left(38^{\circ} \mathrm{C}\right)$ is prolonged, antipyretics could be responsible for inhibiting the immune response and extending the duration. It appears that the use of antipyretic drugs influences the offset time rather than the onset time, shortening the duration to offset time. Antipyretics were associated with a trend toward prolonged duration of illness in a group infected with Shigellasonnei and the influenza virus $[44,45]$. A systematic review indicated that the use of antipyretics in cases of malaria or viral diseases could shorten the duration of fever without prolonging the course of disease $[38,39]$. As noted, the effect of antipyretics on the course of postvaccination fever remains inconclusive, and the effect of antipyretics on postvaccination fever remains unknown. Based on the results of this study, it is possible that antipyretic use may prolong fever duration in children with postvaccination fever.

According to surveys on the use of antipyretics for postvaccination fever prevention and management by parents and caregivers, $11 \%$ of parents administered antipyretics for prophylaxis, and $64 \%$ of parents administered antipyretics for prevention or management within 48 hours of vaccination [46]. Here, after vaccination, $14.66 \%$ of children were administered their first antipyretic drugs within 1 hour and $16.2 \%$ of children were administered antipyretics for fever with a body temperature of less than $38^{\circ} \mathrm{C}$ (Figure 4). This value was higher than in previous studies and may be due to (1) differences in data used in the analysis, (2) cultural differences in the perception of fever, and (3) relative underestimation due to recall bias arising from retrospective survey methods used in prior studies. Also, many parents and caregivers were administering antipyretics for management of postvaccination fever when body temperatures reached $38^{\circ} \mathrm{C}$, most likely because the app instructions advised parents not to administer antipyretics below a body temperature of $38^{\circ} \mathrm{C}$ but rather to administer antipyretics when the body temperature was above $38^{\circ} \mathrm{C}$ depending on the child's condition. Various studies have been conducted on the risks and benefits of using antipyretics for postvaccination fever. Febrile 
convulsions are the most worrying situation for parents and caregivers when fever is present. To prevent convulsions, prophylactic antipyretics and routine antipyretics have been used during fevers, but with no effect on reducing febrile convulsions confirmed $[23,39,47]$. Additionally, several studies have suggested that antipyretics may be associated with decreased immunogenicity, and routine antipyretic administration is no longer recommended for postvaccination fever in countries such as Canada and New Zealand [22,24,48-51]. Alternatively, a systematic review has shown the difficulty of concluding that the reduction in immunogenicity due to antipyretic use does not fall below the seroprotective level and, thus, does not represent actual vaccine failure [48]. A high proportion of antipyretic use for postvaccination fever is believed to be due to fever phobia and a parent's expectation that administering antipyretic drugs will ease a child's discomfort rather than being based on persuasive scientific evidence [52]. Although antipyretic drugs had a temporary effect in lowering body temperature for a mean of 4.4 hours, it is not known whether their use reduced postvaccination fever-related discomfort. To guide the use of antipyretics for alleviating postvaccination fever-related discomfort based on scientific evidence, the effects of antipyretics on fever patterns and child discomfort need to be clarified through double-blinded randomized clinical trials.

\section{Limitations and Future Work}

In our study, fever was defined as a body temperature above $38^{\circ} \mathrm{C}$ regardless of measurement method or age [53]. Although in cases where rectal temperature measurements of $38^{\circ} \mathrm{C}$ or above, or $1^{\circ} \mathrm{C}$ or more above basal body temperature, may be defined as a fever $[35,36]$, rectal temperature measurements are not a readily applicable method of measuring body temperature, and infrared tympanic thermometers, noncontact infrared-forehead thermometers, axillary thermometers, and oral thermometers are most commonly used in practice $[54,55]$ with inconsistent results [56-58]. Body temperature may also vary depending on the age and biological factors of an individual. The dataset used in this study did not contain any information concerning the temperature measurement method or site, and it was difficult to analyze all relevant factors including age and biological factors in relation to temperature measurement. Therefore, we defined a conservative standard for fever as a body temperature greater than $38^{\circ} \mathrm{C}$. This criterion was consistent with the body temperature at which the child was administered the antipyretic drug. A more accurate analysis would be possible using a definition of fever as a body temperature of $1^{\circ} \mathrm{C}$ above the basal body temperature or above $38^{\circ} \mathrm{C}$, as well as obtaining the measurement method and site, and acquiring mandatory data on basal body temperature.
Data used here were obtained by app users directly entering their child's body temperature. Since a uniform standard for measuring body temperatures was not applied (including measurement device and site), questions can be raised concerning the accuracy of the body temperature data. Furthermore, the app is dependent on the user entering the data correctly and consistently.

Despite these limitations, the five vaccines included in this study were more frequently recorded compared to the vaccines that we excluded. It is possible that postvaccination fever is actually more likely to occur due to these vaccines than others, and parents may also have believed that postvaccination fever in relation to these vaccines is more common than with others. Therefore, they may have been more likely to perform body temperature measurements. These limitations could be overcome through wearing thermometers and body temperature recording applications that continuously measure body temperatures before and after vaccination.

In practice, multiple vaccinations are recommended rather than single vaccinations, and more people are having multiple vaccinations, since there are no challenges in obtaining immunogenicity, no increase in side effects, and immunization schedules can be simplified [59]. However, multiple vaccinations may have an effect on postvaccination fever patterns depending on vaccine types. This study focused on single vaccinations; subsequent studies are underway concerning multiple vaccinations.

In our study, an analysis of the use of antipyretic drugs was only conducted after vaccination. However, the postvaccination fever pattern can vary depending on when an antipyretic drug is administered. More detailed research on postvaccination fever patterns is needed to determine when an antipyretic drug is to be administered.

Through creating a model that can predict future progress, based on the natural course of postvaccination fever (Figure 6), postvaccination temperature monitoring can provide useful information to parents, caregivers, and health care professionals, which is likely to reduce unnecessary tests and treatments, and consequently contribute to improvements in children's health.

\section{Conclusion}

Postvaccination fever has its own fever pattern depending on the type of vaccine administered. The pattern of postvaccination fever can be altered using antipyretic drugs, making the diagnosis of postvaccination fever difficult. This study showed that antipyretic drugs may prolong the duration of postvaccination fever, due to routine use or overuse. Postvaccination body temperature observation and comparison with postvaccination fever patterns indicated here may reduce the unnecessary use of antipyretics.

\section{Acknowledgments}

This work was supported by Technology Innovation Program (20002289) funded by the Ministry of Trade, Industry, and Energy (MOTIE, KOREA) and the Basic Science Research Program through the National Research Foundation of Korea (NRF), funded by the Ministry of Education (NRF-2017R1D1A1B03035762). 


\section{Authors' Contributions}

Study concept and design: all authors; data acquisition: SC, JS, and MK; data preprocessing: SHA and JZ; statistical analysis and interpretation: SHA, JZ, HK, YL, JHL, YRP; interpretation of the results: SHA, JS, JHL, YRP; crafting of the manuscript: SHA, JZ, YRP; and study supervision: JS, JHL, YRP.

\section{Conflicts of Interest}

Seyun Chang, Jaewon Shin, and Myeongchan Kim are employees of Mobile Doctor Co, Ltd. All other authors declare no conflicts of interest.

\section{Multimedia Appendix 1}

Screenshots of Fever Coach application translated into English.

[PDF File (Adobe PDF File), 1MB-Multimedia Appendix 1]

\section{Multimedia Appendix 2}

Comparison of onset, offset, and duration times and maximum temperatures among vaccine types and effects of antipyretics on postvaccination fever response.

[DOCX File, 15KB-Multimedia Appendix 2]

\section{References}

1. World Health Organization. WHO recommendations for routine immunization-summary tables URL: https://www.who.int/ immunization/policy/immunization tables/en/ [accessed 2019-03-26] [WebCite Cache ID 77Au79Meh]

2. Kelso JM, Greenhawt MJ, Li JT, Nicklas RA, Bernstein DI, Blessing-Moore J, et al. Adverse reactions to vaccines practice parameter 2012 update. J Allergy Clin Immunol 2012 Jul;130(1):25-43. [doi: 10.1016/j.jaci.2012.04.003] [Medline: 22608573]

3. Zhou W, Pool V, Iskander JK, English-Bullard R, Ball R, Wise RP, et al. Surveillance for safety after immunization: Vaccine Adverse Event Reporting System (VAERS)--United States, 1991-2001. MMWR Surveill Summ 2003 Jan 24;52(1):1-24 [FREE Full text] [Medline: 12825543]

4. Jampel HD, Duff GW, Gershon RK, Atkins E, Durum SK. Fever and immunoregulation. III. Hyperthermia augments the primary in vitro humoral immune response. J Exp Med 1983 Apr 01;157(4):1229-1238 [FREE Full text] [Medline: 6220108]

5. Kluger MJ, Kozak W, Leon LR, Soszynski D, Conn CA. Cytokines and fever. Neuroimmunomodulation 1995 Mar;2(4):216-223. [doi: 10.1159/000097199] [Medline: $\underline{\text { 8963750] }}$

6. Evans SS, Repasky EA, Fisher DT. Fever and the thermal regulation of immunity: the immune system feels the heat. Nat Rev Immunol 2015 Jun;15(6):335-349 [FREE Full text] [doi: 10.1038/nri3843] [Medline: 25976513]

7. Jackson LA, Peterson D, Dunn J, Hambidge SJ, Dunstan M, Starkovich P, et al. A randomized placebo-controlled trial of acetaminophen for prevention of post-vaccination fever in infants. PLoS One 2011 Jun;6(6):e20102 [FREE Full text] [doi: 10.1371/journal.pone.0020102] [Medline: 21698100]

8. Tichmann-Schumann I, Soemantri P, Behre U, Disselhoff J, Mahler H, Maechler G, et al. Immunogenicity and reactogenicity of four doses of diphtheria-tetanus-three-component acellular pertussis-hepatitis B-inactivated polio virus-Haemophilus influenzae type b vaccine coadministered with 7-valent pneumococcal conjugate Vaccine. Pediatr Infect Dis J 2005 Jan;24(1):70-77. [Medline: 15665713]

9. Black S, Shinefield H, Fireman B, Lewis E, Ray P, Hansen JR, et al. Efficacy, safety and immunogenicity of heptavalent pneumococcal conjugate vaccine in children. Northern California Kaiser Permanente Vaccine Study Center Group. Pediatr Infect Dis J 2000 Mar;19(3):187-195. [Medline: 10749457]

10. Jackson LA, Carste BA, Malais D, Froeschle J. Retrospective population-based assessment of medically attended injection site reactions, seizures, allergic responses and febrile episodes after acellular pertussis vaccine combined with diphtheria and tetanus toxoids. Pediatr Infect Dis J 2002 Aug;21(8):781-786. [doi: 10.1097/01.inf.0000024003.77163.3d] [Medline: 12192169]

11. de Martino M, Chiarugi A. Recent advances in pediatric use of oral paracetamol in fever and pain management. Pain Ther 2015 Dec;4(2):149-168 [FREE Full text] [doi: 10.1007/s40122-015-0040-z] [Medline: 26518691]

12. Tapiainen T, Heininger U. Fever following immunization. Expert Rev Vaccines 2005 Jun;4(3):419-427. [doi: 10.1586/14760584.4.3.419] [Medline: 16026253]

13. Crocetti M, Moghbeli N, Serwint J. Fever phobia revisited: have parental misconceptions about fever changed in 20 years? Pediatrics 2001 Jun 01;107(6):1241-1246. [doi: 10.1542/peds.107.6.1241]

14. Gunduz S, Usak E, Koksal T, Canbal M. Why fever phobia is still common? Iran Red Crescent Med J 2016 Aug;18(8):e23827 [FREE Full text] [doi: 10.5812/ircmj.23827] [Medline: 27781110] 
15. Kwak YH, Kim DK, Jang HY, Kim JJ, Ryu J, Oh SB, et al. Fever phobia in Korean caregivers and its clinical implications. J Korean Med Sci 2013 Nov;28(11):1639-1644 [FREE Full text] [doi: 10.3346/jkms.2013.28.11.1639] [Medline: 24265528]

16. Smith LE, Webster RK, Weinman J, Amlôt R, Yiend J, Rubin GJ. Psychological factors associated with uptake of the childhood influenza vaccine and perception of post-vaccination side-effects: A cross-sectional survey in England. Vaccine 2017 Dec 04;35(15):1936-1945 [FREE Full text] [doi: 10.1016/j.vaccine.2017.02.031] [Medline: 28284680]

17. Zhang L, Prietsch SO, Axelsson I, Halperin SA. Acellular vaccines for preventing whooping cough in children. Cochrane Database Syst Rev 2014 Sep 17(9):CD001478. [doi: 10.1002/14651858.CD001478.pub6] [Medline: 25228233]

18. Stockwell MS, Broder K, LaRussa P, Lewis P, Fernandez N, Sharma D, et al. Risk of fever after pediatric trivalent inactivated influenza vaccine and 13-valent pneumococcal conjugate vaccine. JAMA Pediatr 2014 Mar;168(3):211-219. [doi: 10.1001/jamapediatrics.2013.4469] [Medline: 24395025]

19. Bryant KA, Block SL, Baker SA, Gruber WC, Scott DA, PCV13 Infant Study Group. Safety and immunogenicity of a 13-valent pneumococcal conjugate vaccine. Pediatrics 2010 May;125(5):866-875. [doi: 10.1542/peds.2009-1405] [Medline: 20435707]

20. Cunha BA. The clinical significance of fever patterns. Infect Dis Clin North Am 1996 Mar;10(1):33-44. [Medline: $\underline{8698993]}$

21. Ogoina D. Fever, fever patterns and diseases called 'fever'--a review. J Infect Public Health 2011 Aug;4(3):108-124 [FREE Full text] [doi: 10.1016/j.jiph.2011.05.002] [Medline: 21843857]

22. Kirubakaran R, Viswanathan A, Kompithra R. Prophylactic paracetamol for the prevention of fever in children receiving vaccination as part of a standard childhood immunization schedule. Cochrane Database Syst Rev 2017 May 05(5):CD012655. [doi: 10.1002/14651858.CD012655]

23. Monfries N, Goldman R. Prophylactic antipyretics for prevention of febrile seizures following vaccination. Can Fam Physician 2017 Feb;63(2):128-130 [FREE Full text] [Medline: 28209678]

24. Yeh SH, Gurtman A, Hurley DC, Block SL, Schwartz RH, Patterson S, 004 Study Group. Immunogenicity and safety of 13-valent pneumococcal conjugate vaccine in infants and toddlers. Pediatrics 2010 Sep;126(3):e493-e505. [doi: 10.1542/peds.2009-3027] [Medline: 20732948]

25. Aronoff DM, Neilson EG. Antipyretics: mechanisms of action and clinical use in fever suppression. Am J Med 2001 Sep;111(4):304-315. [Medline: 11566461]

26. Kumar RB, Goren ND, Stark DE, Wall DP, Longhurst CA. Automated integration of continuous glucose monitor data in the electronic health record using consumer technology. J Am Med Inform Assoc 2016 May;23(3):532-537 [FREE Full text] [doi: 10.1093/jamia/ocv206] [Medline: 27018263]

27. Jang I, Kim H, Lee E, Jung H, Park H, Cheon S, et al. Impact of a wearable device-based walking programs in rural older adults on physical activity and health outcomes: cohort study. JMIR Mhealth Uhealth 2018 Nov 21;6(11):e11335 [FREE Full text] [doi: 10.2196/11335] [Medline: 30463838]

28. Kim J, Kam HJ, Park YR, Yoo S, Oh JS, Kim Y, et al. Enchanted life space: adding value to smart health by integrating human desires. Healthc Inform Res 2018 Jan;24(1):3-11 [FREE Full text] [doi: 10.4258/hir.2018.24.1.3] [Medline: 29503747]

29. Park YR, Lee Y, Kim JY, Kim J, Kim HR, Kim Y, et al. Managing patient-generated health data through mobile personal health records: analysis of usage data. JMIR Mhealth Uhealth 2018 Apr 09;6(4):e89 [FREE Full text] [doi: 10.2196/mhealth.9620] [Medline: 29631989]

30. Walker DM, Sieck CJ, Menser T, Huerta TR, Scheck MA. Information technology to support patient engagement: where do we stand and where can we go? J Am Med Inform Assoc 2017 Nov 01;24(6):1088-1094. [doi: 10.1093/jamia/ocx043] [Medline: 28460042]

31. Torkamani A, Andersen KG, Steinhubl SR, Topol EJ. High-definition medicine. Cell 2017 Aug 24;170(5):828-843 [FREE Full text] [doi: 10.1016/j.cell.2017.08.007] [Medline: 28841416]

32. Cohen D, Keller S, Hayes G, Dorr D, Ash J, Sittig D. Integrating patient-generated health data into clinical care settings or clinical decision-making: lessons learned from project health and design. JMIR Hum Factors 2016 Oct 19;3(2):e26 [FREE Full text] [doi: 10.2196/humanfactors.5919] [Medline: 27760726]

33. Accenture Federal Services. Conceptualizing a Data Infrastructure for the Capture, Use, and Sharing of Patient-Generated Health Data in Care Delivery and Research through 2024: Draft White Paper for a PGHD Policy Framework. Washington, DC: Office of the National Coordinator for Health Information Technology; 2018 Jan. URL: https://www.healthit.gov/sites/ default/files/onc_pghd_practical_guide.pdf [accessed 2019-04-01] [WebCite Cache ID 77JCtKSMs]

34. World Health Organization. Supplementary Information on Vaccine Safety. Part 2: Background Rates of Adverse Events Following Immunization. Geneva: World Health Organization; 2000. URL: https://apps.who.int/iris/handle/10665/66675 [accessed 2019-03-26] [WebCite Cache ID 77Ay9nYu1]

35. National Institute for Health and Care Excellence. 2013. Fever in under 5s: assessment and initial management URL: https:/ /www.nice.org.uk/guidance/CG160 [accessed 2019-03-26] [WebCite Cache ID 77AyHFksp]

36. Craig JV, Lancaster GA, Taylor S, Williamson PR, Smyth RL. Infrared ear thermometry compared with rectal thermometry in children: a systematic review. Lancet 2002 Aug 24;360(9333):603-609. [doi: 10.1016/S0140-6736(02)09783-0] [Medline: 12241932]

37. Centers for Disease Control and Prevention. 2018. Ingredients of vaccines-fact sheet URL: https://www.cdc.gov/vaccines/ vac-gen/additives.htm [accessed 2019-03-26] [WebCite Cache ID 77AyNhktg] 
38. Harris G, Nolan T, Hartman L. Clinical signs associated with Triple Antigen (DTP) vaccination in infants. J Paediatr Child Health 1995 Jun;31(3):228-232. [Medline: 7669385]

39. Prymula R, Siegrist C, Chlibek R, Zemlickova H, Vackova M, Smetana J, et al. Effect of prophylactic paracetamol administration at time of vaccination on febrile reactions and antibody responses in children: two open-label, randomised controlled trials. Lancet 2009 Oct 17;374(9698):1339-1350. [doi: 10.1016/S0140-6736(09)61208-3] [Medline: 19837254]

40. Allotey P, Reidpath DD, Elisha D. "Social medication" and the control of children: a qualitative study of over-the-counter medication among Australian children. Pediatrics 2004 Sep;114(3):e378-e383. [doi: 10.1542/peds.2004-0759] [Medline: 15342901]

41. Enarson M, Ali S, Vandermeer B, Wright R, Klassen T, Spiers J. Beliefs and expectations of Canadian parents who bring febrile children for medical care. Pediatrics 2012 Oct;130(4):e905-e912. [doi: 10.1542/peds.2011-2140] [Medline: 22966028]

42. Voysey M, Barker CI, Snape MD, Kelly DF, Trück J, Pollard AJ. Sex-dependent immune responses to infant vaccination: an individual participant data meta-analysis of antibody and memory B cells. Vaccine 2016 Mar 29;34(14):1657-1664. [doi: 10.1016/j.vaccine.2016.02.036] [Medline: 26920472]

43. Jørgensen TN. Sex disparities in the immune response. Cell Immunol 2015 Apr;294(2):61-62. [doi: 10.1016/j.cellimm.2015.02.001] [Medline: 25670393]

44. Jefferies S, Weatherall M, Young P, Eyers S, Perrin KG, Beasley CR. The effect of antipyretic medications on mortality in critically ill patients with infection: a systematic review and meta-analysis. Crit Care Resusc 2011 Jun;13(2):125-131. [Medline: 21627583]

45. Hudgings L, Kelsberg G, Safranek S, Neher JO. Clinical inquiries. Do antipyretics prolong febrile illness? J Fam Pract 2004 Jan;53(1):57-58, 61. [Medline: 14709270 ]

46. Saleh E, Swamy GK, Moody MA, Walter EB. Parental approach to the prevention and management of fever and pain following childhood immunizations: a survey study. Clin Pediatr (Phila) 2017 May;56(5):435-442 [FREE Full text] [doi: 10.1177/0009922816675116] [Medline: 27798399]

47. Rosenbloom E, Finkelstein Y, Adams-Webber T, Kozer E. Do antipyretics prevent the recurrence of febrile seizures in children? A systematic review of randomized controlled trials and meta-analysis. Eur J Paediatr Neurol 2013 Nov;17(6):585-588. [doi: 10.1016/j.ejpn.2013.04.008] [Medline: 23702315]

48. Das RR, Panigrahi I, Naik SS. The effect of prophylactic antipyretic administration on post-vaccination adverse reactions and antibody response in children: a systematic review. PLoS One 2014 Sep;9(9):e106629 [FREE Full text] [doi: 10.1371/journal.pone.0106629] [Medline: 25180516]

49. Falup-Pecurariu O, Man SC, Neamtu ML, Chicin G, Baciu G, Pitic C, et al. Effects of prophylactic ibuprofen and paracetamol administration on the immunogenicity and reactogenicity of the 10-valent pneumococcal non-typeable Haemophilus influenzae protein D conjugated vaccine (PHiD-CV) co-administered with DTPa-combined vaccines in children: An open-label, randomized, controlled, non-inferiority trial. Hum Vaccin Immunother 2017 Dec 04;13(3):649-660 [FREE Full text] [doi: 10.1080/21645515.2016.1223001] [Medline: 27541270]

50. Government of Canada, Public Health Agency of Canada. 2018. Canadian immunization guide URL: https://www.canada.ca/ en/public-health/services/canadian-immunization-guide.html [accessed 2019-03-26] [WebCite Cache ID 77Ayl8KF9]

51. Ministry of Health. 2015. Tips following immunisation URL: https://www.health.govt.nz/your-health/healthy-living/ immunisation/tips-following-immunisation [accessed 2019-03-26] [WebCite Cache ID 77AzWqUtO]

52. Section on Clinical Pharmacology and Therapeutics, Committee on Drugs, Sullivan JE, Farrar HC. Fever and antipyretic use in children. Pediatrics 2011 Mar;127(3):580-587. [doi: 10.1542/peds.2010-3852] [Medline: 21357332]

53. Mackowiak PA, Worden G. Carl Reinhold August Wunderlich and the evolution of clinical thermometry. Clin Infect Dis 1994 Mar;18(3):458-467. [Medline: $\underline{\text { 8011836] }}$

54. Craig JV, Lancaster GA, Williamson PR, Smyth RL. Temperature measured at the axilla compared with rectum in children and young people: systematic review. BMJ 2000 Apr 29;320(7243):1174-1178 [FREE Full text] [Medline: 10784539]

55. Leick-Rude MK, Bloom LF. A comparison of temperature-taking methods in neonates. Neonatal Netw 1998 Aug;17(5):21-37. [Medline: 9791443]

56. Berksoy E, Anıl M, Bıcılıŏlu Y, Gökalp G, Bal A. Comparison of infrared tympanic, non-contact infrared skin, and axillary thermometer to rectal temperature measurements in a pediatric emergency observation unit. Int J Clin Exp Med 2018;11(2):567-573 [FREE Full text]

57. Teller J, Ragazzi M, Simonetti GD, Lava SA. Accuracy of tympanic and forehead thermometers in private paediatric practice. Acta Paediatr 2014 Feb;103(2):e80-e83. [doi: 10.1111/apa.12464] [Medline: 24127699]

58. Brown RD, Kearns G, Eichler VF, Wilson JT. A probability nomogram to predict rectal temperature in children. Clin Pediatr (Phila) 1992 Sep;31(9):523-531. [doi: 10.1177/000992289203100902] [Medline: 1468168]

59. Centers for Disease Control and Prevention. 2018. Multiple vaccines and the immune system URL: https://www.cdc.gov/ vaccinesafety/concerns/multiple-vaccines-immunity.html [accessed 2019-03-26] [WebCite Cache ID 77Av3jAdS]

\author{
Abbreviations \\ BCG: bacillus Calmette-Guérin
}


CI: confidence interval

DTaP: diphtheria, tetanus, and pertussis

HIB: Haemophilus influenzae type B

IQR: interquartile range

MMR: measles-mumps-rubella

PGHD: patient-generated health data

VIF: variance inflation factor

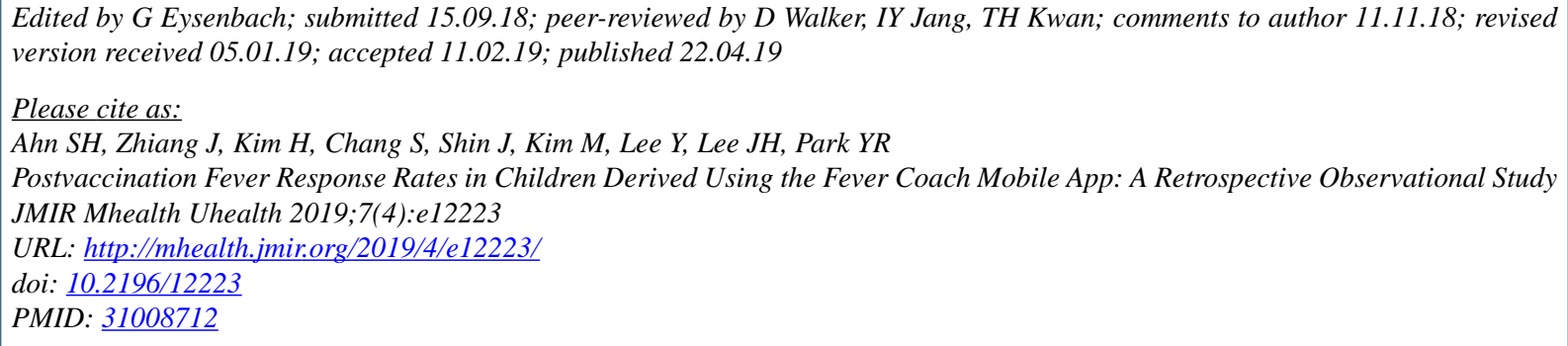

(OSang Hyun Ahn, Jooho Zhiang, Hyery Kim, Seyun Chang, Jaewon Shin, Myeongchan Kim, Yura Lee, Jae-Ho Lee, Yu Rang Park. Originally published in JMIR Mhealth and Uhealth (http://mhealth.jmir.org), 22.04.2019. This is an open-access article distributed under the terms of the Creative Commons Attribution License (https://creativecommons.org/licenses/by/4.0/), which permits unrestricted use, distribution, and reproduction in any medium, provided the original work, first published in JMIR mhealth and uhealth, is properly cited. The complete bibliographic information, a link to the original publication on http://mhealth.jmir.org/, as well as this copyright and license information must be included. 